\title{
The Effect of Soil Particle Arrangement on Shear Strength Behavior of Silty Sand
}

\author{
Nik Daud Nik Norsyahariati ${ }^{1, a}$, Kam Ru Hui ${ }^{1}$ and Abd Ghafar Azmi Juliana ${ }^{1}$ \\ ${ }^{1}$ Department of Civil Engineering, Faculty of Engineering, Universiti Putra Malaysia, 43400 Serdang, Selangor, \\ Malaysia
}

\begin{abstract}
The presence of fines in sandy soil is recognized as a problem in geotechnical engineering. It is often assumed that the strength and liquefaction potential of a soil decreases with increasing fines content. Sand with a significant amount of fines is always encountered in geotechnical engineering projects. The main interest of this paper is to study the effect of particles arrangement and stress behaviour on sand and silty sand sample. The objectives are to determine the basic properties as well as the morphological and mineralogical properties and the relationship of those properties to the stress behaviour of the soils. Sand-silt mixtures with fines contents of $20 \%$ and $40 \%$ were prepared and a series of testing was carried out to determine their basic properties, morphological and thin section properties, and mechanical properties by using direct shear box equipment. Results show that the basic properties and morphological properties of soil affect the mechanical behaviour of soil. Shape of the soil particle can influence the packing of the soil, hence altering the mechanical behaviour of the soil. From the thin section, the soil is observed to be well graded and have a dense packing while the minerals observed were mainly quartz and rutile.
\end{abstract}

\section{Introduction}

Most of the natural and man-made soil deposits contain a certain amount of silt and/or clay. Due to increasing of shortage of clean sands near project locations, the use of mixed sand, which includes silty sand, clayey sand, sandy clay and sandy silt, will be practical option in reclamation works. Fines may also be produced during dredging process itself, causing the clean sands to contain a certain amount of fines.

The presence of fines in sandy soil is recognized as a problem in geotechnical engineering. It is often assumed that the strength of a soil decreases with increasing fines content. However, regarding to the liquefaction potential it is not a drawback, indeed it is advantage in geotechnical application. Thus, the maximum fines content is usually limited to $10 \%$ only in most geotechnical projects. It has been recognized that the availability of soils which have small amount of fines is very rare. In most of projects soil with maximum amount of fines above $10 \%$ are encountered.

The shape of soil grains affects the engineering behaviour of the soils. Round grains are more likely to slip and roll than angular fragments. Natural sand and crushed sand has difference shape. Natural sand has the roundness and roughness. The shape of natural sand can be altered during

\footnotetext{
${ }^{a}$ Corresponding author : niknor@upm.edu.my
} 
transportation or through weathering. On the other hand, crushed quartz sand tends to be equidimensional or elongated in shape. This is because quartz has no cleavage. Particle rotation is a basic component of deformation during compressibility of granular materials [1], which is affected by the shape of the grains. As the angularity increases, the ratio of rolling to sliding contacts decreases, which leads to greater shearing resistance [2]. Dense packing enhances the effect of angularity. The total number of contacts between particles increases and cause the rotation resistance increases. In shear behaviour, the friction angle can be affected by the gradation of sand such as sands with the lowest friction angle tend to be medium-fine, well-rounded, and poorly graded sands and Sands with the highest friction angle tend to be coarser grained, well-graded, and/or angular sands [3]. The addition of non-plastic silt to the host sand increases both the peak and critical-state friction angles of the soil [4]. It appears that the more angular non-plastic silt particles tend to interact with irregularities on the surface of sand particles, increasing the "jamming" effect during shearing.

The aim of this study is to study the stress behaviour on silty sand with the relation toward the particle arrangement. Specific objectives are (i) To determine the basic properties of sand with varying silt content, (ii) To determine the morphological and thin section properties of the soils and (iii) To analyze the effect of silt content on the strength behavior of the soil.

\section{Materials and Methods}

\subsection{Materials}

Silty sand is collected from Tasik Angsana, Sungai Pelik, Sepang, Selangor (GPS coordinate: $\left.2^{\circ} 37^{\prime} 21.9^{\prime \prime} \mathrm{N} 101^{\circ} 42^{\prime} 00.1^{\prime \prime} \mathrm{E}\right)$ as indicated with a red pointer in Figure 1. There was no vegetation on the surface of the soil, so the top soil layer was scraped away and the soil sample was collected from the sub soil layer using a shovel.

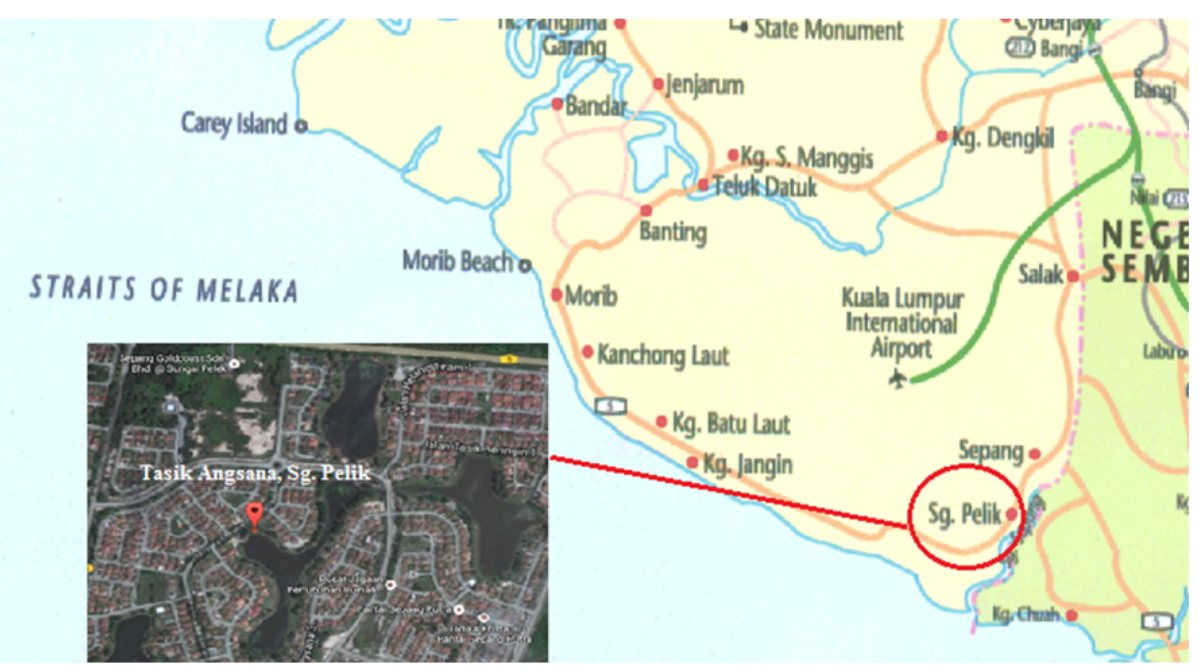

Figure 1. Soil sampling location (Source: Google Maps).

\subsection{Methods}

The soil is oven-dried at an average $105^{\circ} \mathrm{C}$ and then sieved in order to obtain sand (particle retained $0.063 \mathrm{~mm}$ sieve) and silt (particle passed $0.063 \mathrm{~mm}$ sieve) portion. The fines and the coarse fraction were reconstituted in varying proportions of fines to coarse ratios to study the effects of silt content on the stress behaviour of sands, from $20 \%$ silt; $80 \%$ sand and $40 \%$ silt; $60 \%$ sand. Since the natural 
soil has $20 \%$ silt and $80 \%$ sand, the soil is not altered or remixed. Sample of $40 \%$ silt $60 \%$ sand was produced by mixing the clean sand and pure silt by weight.

A complete basic properties testing program was performed on all the sand-silt mixtures based on standard [5]. Basic properties including grain size distribution, specific gravity, linear shrinkage, liquid limit and plastic limit were determined for the each sand-silt mixture. Morphological and mineralogical properties testing program was performed on the natural soil sample, which is $20 \%$ silt and $80 \%$ sand. Morphological properites of the samples were determined by using Scanning Electron Microscope - SEM (Hitachi S-3400N Variable Pressure) and mineralogical properties were determined by using and thin section procedure. The thin sections were produced according to well established methods $[6,7]$; although modified as necessary to accommodate the delicate nature of the oil sands with a view to preserving its integrity and minimizing alterations of the oil hosted in the quartz rich samples during the course of thin section production [8]. Thin sections were done by mixing the oven dried soil sample at an average $105^{\circ} \mathrm{C}$ with epoxy in a plastic mould and left 24 hours at room temperature to harden as shown in Figure 2(a). The hardened block is then cut into a smaller block then glued to a glass slide with epoxy and left to cure for 24 hours at room temperature as shown in. The block of sample on the glass slide is then filed down to $1 \mathrm{~mm}$ thick as shown in Figure 2(b). The thin section is then viewed under a polarized light microscope at different magnifications to observe the soil structure, soil matrix and minerals present in the soil.
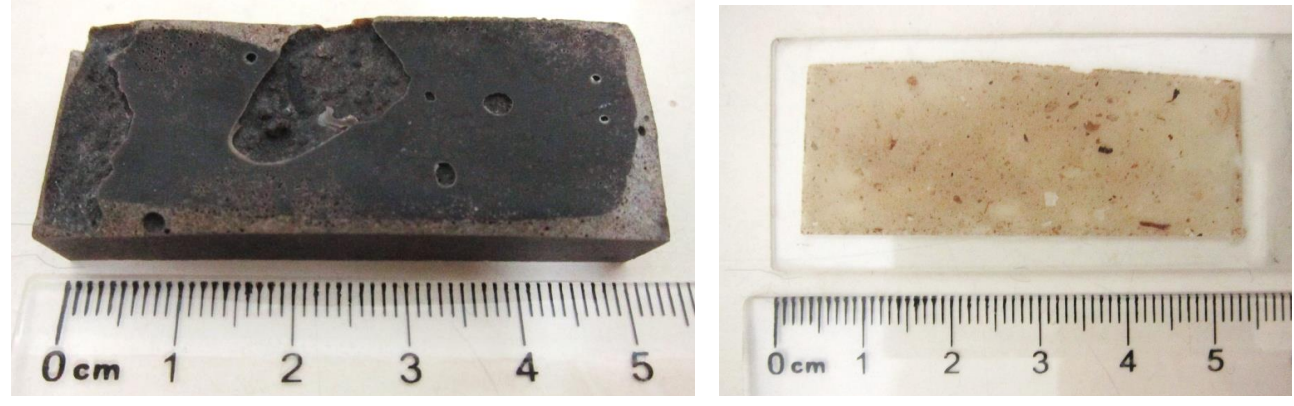

Figure 2. (a) Hardened sample of the natural soil sample (20\% silt, $80 \%$ sand) mixed with epoxy, (b) Thin section slide of the soil sample.

A series of direct shear box test (TKA-DDS-5C Microprocessor-controlled Direct Shear Apparatus) were carried out on each of the sand-silt mixture to determine the stress behavior of the soils. The procedures of the test were referred to BS 1377.

\section{Results and Discussion}

The findings on the basic properties will be discussed in this section, followed by the morphological and mineralogical properties, and finally detailed analysis and discussion on the stress behaviour of the soils.

\subsection{Basic properties}

Several basic properties testing including grain size distribution, specific gravity, linear shrinkage, liquid limit, plastic limit and compaction test were carried out. The initial moisture content of natural soil sample collected ( $20 \%$ silt, $80 \%$ sand) was $21.16 \%$. Table 1 shows as the silt content in sand increases, the liquid limit, the maximum dry density and optimum moisture content increases. It is shows that fines percentages gave a significant effect to the related properties. The detailed results of all basic properties are tabulated in Table 1 . 
Table 1. Index properties of sand- silt mixture samples.

\begin{tabular}{|l|c|c|}
\hline Silt content in sand (\%) & $\mathbf{2 0}$ & $\mathbf{4 0}$ \\
\hline USCS classification & SM & SM \\
\hline Coefficient of uniformity, $C_{u}$ & 2.000 & 3.385 \\
\hline Coefficient of curvature, $C_{c}$ & 28.000 & 43.706 \\
\hline Specific gravity, $G_{s}$ & 2.70 & 2.71 \\
\hline Liquid limit (\%) & 24.40 & 25.32 \\
\hline Plastic limit (\%) & 23.96 & 24.78 \\
\hline Plasticity index (\%) & 0.44 & 0.54 \\
\hline Maximum dry density $\left(\mathrm{Mg} / \mathrm{m}^{3}\right)$ & 1.62 & 1.69 \\
\hline Optimum moisture content $(\%)$ & 10.5 & 10.8 \\
\hline
\end{tabular}

*USCS - Unified Soil Classification System; SM - silty sand

The specific surface area value for the natural soil sample (20\% silt, $80 \%$ sand) is $1.986 \mathrm{~m}^{2} / \mathrm{g}$. The relatively low value indicates that the soil mostly consist of sand and has a relatively high permeability and is slightly plastic.

\subsection{Morphological and mineralogical properties}

From the Scanning Electron Microscope (SEM) image in Figure 3 and thin section image (Figure 4), silt and sand particles shape are observed and compared to the designated chart [9] in order to determine the roundness and sphericity of a soil particle.

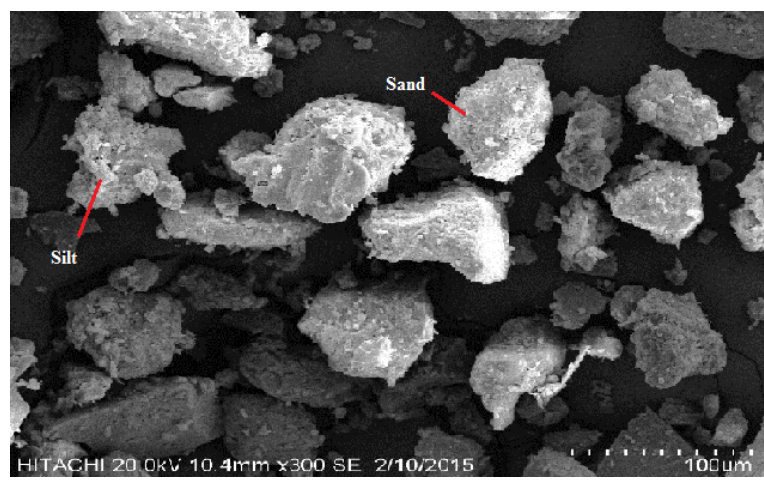

Figure 3. SEM image of the natural soil sample oven-dried at an average $105^{\circ} \mathrm{C}$ at $300 \times$ magnification.

It can be observed that the particle is basically sub-angular and has a medium sphericity. The surface of the soil particles generally has a semi-rough texture. Since the soil particles are sub-angular, the ratio of rolling to sliding contacts is decreased leading to greater shearing resistance. The effect of angularity is enhanced for dense packing. The total number of contacts between particles increases and as a result, the rotation resistance increases, leading to the rotational frustration. 


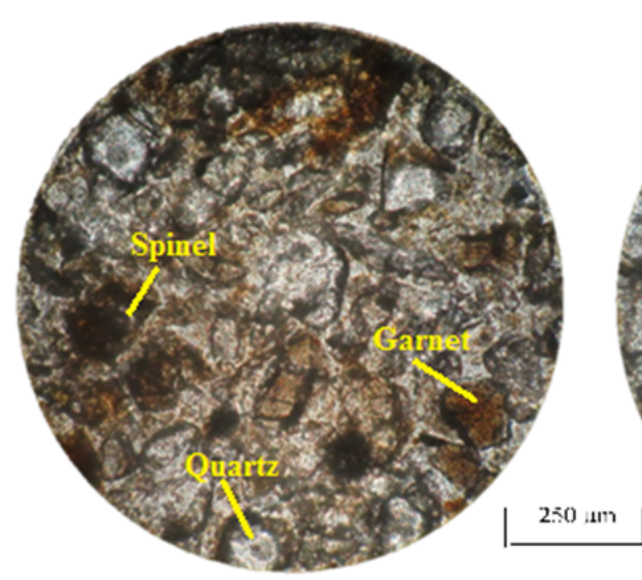

(a)

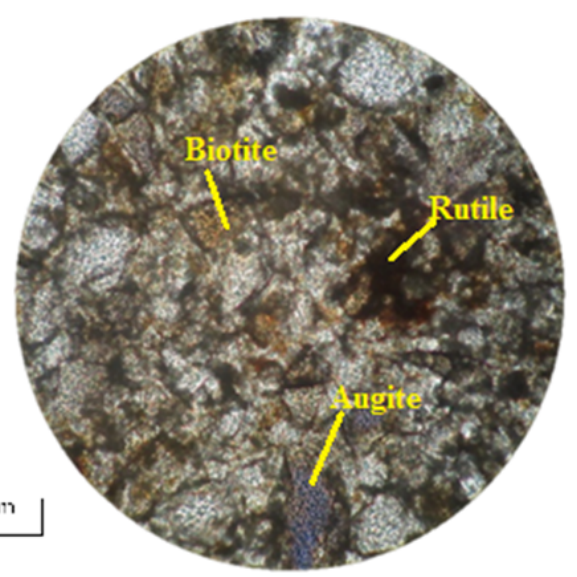

(b)

Figure 4. Random sampling on the thin section at $400 \times$ magnification of the natural soil sample.

The soil structure is generally comprised of sand and silt indicated with yellow arrows in the figure. The shapes of the sand grains are mostly sub-angular and medium sphericity, similar to the observations from the SEM photograph. The variation of sand and silt particles cause the arrangement of soil to have a fairly dense packing and this contributes to the stress behaviour of the soil [10]. The sample is also randomly sampled at different spot on the slide to determine the minerals present in the soil (Figure 4).

By referring to the mineral identification table [11], minerals observed in the thin section are quartz, rutile, spinel, garnet, augite and biotite. Using an X-ray diffractometer equipment, the dominant mineral identified in the sample is quartz. According to the minerals present in the sample, most of the minerals also appears in granite rock such as quartz and biotite [12] and it can be summarized that samples used for this study are originate from an igneous parent rock.

\subsection{Shear strength properties}

The results from the direct shear tests were analysed and the shear strength parameters were determined by using Mohr's circles (Figure 5) for each sand-silt mixture at different stresses (100 and $300 \mathrm{kPa}$ ). The cohesion, friction angle and shear strength and normal stress at failure point of each sample are determined and summarised in Table 2.

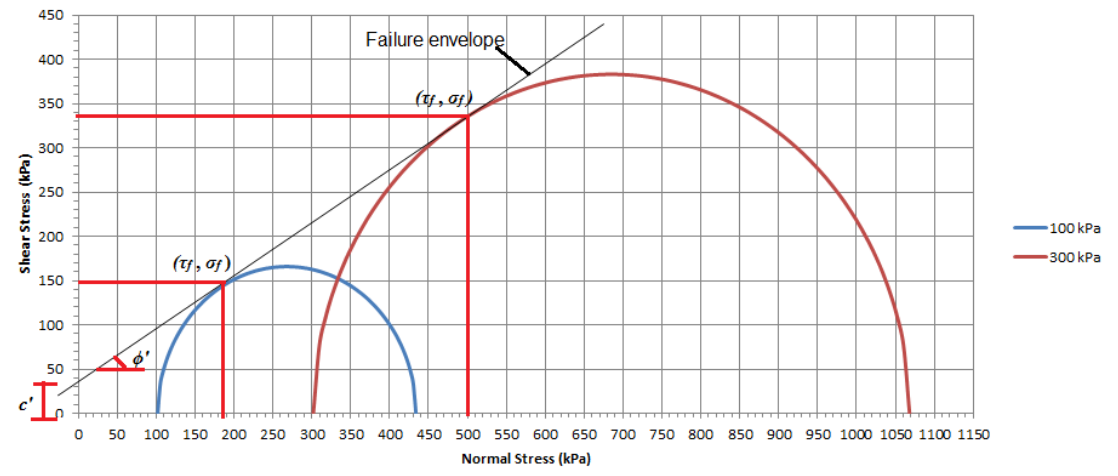

Figure 5. Stress conditions at failure the natural soil sample (20\% silt, $80 \%$ sand). 
Table 2. Shear strength parameters for silty sand samples.

\begin{tabular}{|c|c|c|c|c|c|c|}
\hline \multirow{2}{*}{ Silt Content } & \multirow{2}{*}{$\begin{array}{l}\text { Cohesion, } c^{\prime} \\
\quad \text { (kPa) }\end{array}$} & \multirow{2}{*}{$\begin{array}{c}\text { Friction angle, } \phi^{\prime} \\
\left({ }^{\circ}\right)\end{array}$} & \multicolumn{2}{|c|}{$\begin{array}{c}\text { Shear strength, } \tau_{f} \\
(\mathrm{kPa})\end{array}$} & \multicolumn{2}{|c|}{$\begin{array}{c}\text { Normal stress, } \sigma_{f} \\
(\mathbf{k P a})\end{array}$} \\
\hline & & & 100 & 300 & 100 & 300 \\
\hline $20 \%$ & 38.407 & $31.479^{\circ}$ & 150 & 350 & 180 & 500 \\
\hline $40 \%$ & 60.235 & $27.686^{\circ}$ & 180 & 380 & 210 & 530 \\
\hline
\end{tabular}

It is observed that the shear stress is higher in the sample with $40 \%$ silt content. As the silt content in sand increases, the cohesion of the soil increase, while the friction angle decreases. This is due to the gradation of the soil samples and the shape of soil particles [13]. Since the shape of the soil particles are the same in all the samples, the gradation will be compared. In sample of $20 \%$ silt content, there were sufficient fines to support the sand particles to prevent sliding and rolling. However, at $40 \%$ silt content, the silt particles are more dominant in contributing to the stress behaviour. Therefore, the friction angle is lower. Cohesion of the $20 \%$ silt content sample is much lower compared to the $40 \%$ silt content sample. Obviously, this is because there are more fine particles with higher surface area.

\section{Conclusions}

The purpose of this study is to find out the stress behaviour of silty sand. A series of experiment has been carried out and analysed. The following conclusions can be obtained from the results of the experimental work.

a) The basic properties of soil affect the mechanical behaviour of soil. The gradation of the soils affects the packing of the soils, causing them to exhibit different strengths.

b) The morphological and mineralogical properties of soil particles affect the mechanical behaviour of soil. Shape of the soil particle can influence the packing of the soil, hence altering the mechanical behaviour of the soil. The minerals available in the soil may also contribute to the strength of the soil.

c) Direct shear box test results shows that the friction angle of soil increases then decreases as the fine content increases. Cohesion of soil also increases then decreases as fine contents increases. This is mainly due to the packing of the soil particles.

\section{Acknowledgement}

This study has been funded by Fundamental Research Grant Scheme-FRGS (No.: 03-01-13-1172FR) granted by Ministry of Education (MOE), Malaysia. The help and assistance various governmental and non-governmental organizations in this study are gratefully acknowledged.

\section{References}

[1] G. Mesri and B. Vardhanabhuti, Compression of granular materials, Canadian Geotechnical, 369392, (2009).

[2] K. Mair, K.M. Frye and C. Maronez, Influence of grain characteristics on the friction of granular shear zones, Journal of Geophysical Research, 107(10), 41 - 49, (2002).

[3] C.A. Bareither, T.B. Edil, C.H. Benson and D.M. Mickelson, Geological and physical factors affecting the friction angle of compacted sands, Journal of Geotechnical and Geoenvironmental Engineering, 134(10), 1476-1489, (2008).

[4] J.A. Carraro, M. Prezzi and R. Salgado, Shear strength and stiffness of sands containing plastic or nonplastic fines, Journal of Geotechnical and Geoenvironmental Engineering, 135(9), 1167-1178, (2009). 
[5] BS 1377, Methods of Test for Soils for Civil Engineering Purposes, British Standard Institution, London, (1990).

[6] A. Jongerius and G. Heintzberger, Methods in soil micromorphology, a technique for the preparation of large thin sections, Soil Survey Institute, Netherlands, (1975).

[7] E.A. Fitzpatrick, Micromorphology of Soils, Chapman and Hall, London, (1984).

[8] J.D. Bell, O. Eruteya and O. Oono, Application of petrographic image analysis and multivariate statistical techniques for textural studies of oil sand samples, Annual Convention and Exhibition, Long Beach, 2012).

[9] N.A. Miller and J.J. Henderson, Correlating particle shape parameters to bulk properties and load stress at two water contents, Agronomy Journal, 103(5), 1514-1523, (2011).

[10] C.A. Hecht, Geomechanical models for clastic grain packing, Pure Appl. Geophysic, 161, 331$349,(2004)$.

[11]J. Faithfull, Identification tables for common minerals in thin section, (1998). < retrieved from http://www.hmag.gla.ac.uk/john/teaching/mintable.htm.> (accessed on June, 2015).

[12] G. Vahid, O. Husaini, M.Y. Zainuddin, K.H. Bujang, M. Ratnasamy and N.A. Mohd, A new model of microcracks propagation in granite rock, Australian Journal of Basic and Applied Sciences, (2010).

[13]A.B. Christopher, B.E. Tuncer, H.B. Craig and M.M. David, Geological and physical factors affecting the friction angle of compacted sands, Journal of Geotechnical and Geoenvironmental Engineering, 134(10), 1476 - 1489, (2008). 